\title{
Foramen Magnum-An Important Tool In Morphometry And Surgical Procedures- Part 1
}

\author{
Authors \\ Dr Sandeep Arora, Dr Jasveen Kaur, Dr Harsimran Grewal, \\ Dr Simmi Khatri \\ Corresponding Author
}

Dr Sandeep Arora

Assistant Professor, Department of Anatomy, Sri Venkateshwara Medical College Hospital and Research Centre, Ariyur, Puducherry

ABSTRACT
The study was designed to measure the diameters of foramen Magnum and correlate the measurements with
clinical importance. Even among Indians there was difference noted, so the operating surgeon should keep in
mind the differences in measurements.
Key Words; Foramen Magnum, Base Of Skull, Morphometry

\section{Introduction}

The skull base is a platform at the bottom of the cranium that cradles the brain, provides support, protection and serves as the entrance and exist for major vascular and neural structures. ${ }^{[1]}$

The foramen magnum (FM) lies in an anteromedian position and leads into the posterior cranial fossa. It is oval and wider behind, with its greatest diameter being anteroposterior. It contains the lower end of the medulla oblongata, meninges, vertebral arteries and spinal accessory nerve. The apical ligament of dens and the tectorial membrane pass through it, to attach to the basiocciput. Anteriorly the margin of foramen magnum is slightly overlapped by the occipital condyles. ${ }^{[2]}$

Transcondylar, supracondylar, and other lateral surgical approaches provide access to various foramina on the base of skull and prevent broad retraction of the neural structures passing through them ${ }^{[3]}$
The transcondylar approach is being increasingly used to access lesions ventral to the brainstem and cervicomedullary junction. Understanding the bony anatomy of this region is important for this approach. ${ }^{[4]}$ The space-occupying lesion ventral to the spinal canal at the level of the foramen magnum can be reached using a ventral or dorsal approach. The difficulties and high rate of morbidity associated with ventral approaches dictates to use a dorsal approach to the ventral processes of the fora- men magnum. Such an approach needs a transcondylar approach. Partial resection of the occipital condyle, as made duringtranscondylar surgicalapproaches, hasbeen an important step for access to the ventral and ventrolateral foramen magnum ${ }^{[5]}$.

It is well known that measurements of bone are useful in Anthropology. Many important nerves and vessels pass in and out of the skull via openings termed foramina. ${ }^{[2]}$ 


\section{JMSCR Vol||04||Issue||08||Page 11876-11883||August}

Advancements in micro surgical techniques have made possible the removal of advanced jugular foramen lesions, which were one assumed to be inoperable. As neuro Surgeons become bolder in approaching this region, so the need for familarity with the detailed anatomy of this region becomes greater. The difficulties in exposing this foramen are created by its deep location \& the surrounding vital structures, such as the carotid ortery anteriorly, the hypoglassal nerve medially, the facial nerve laterally and the vertebral ortery inferiorly. All these important structures require carefull dissection during acess to this foramen. ${ }^{[6]}$ Modern surgical procedure, anesthesia, as well as acupuncture practice, require more precise understanding of the surrounding anatomy of various foramina. ${ }^{[7]}$

Many important nerves and vessels pass in and out of the skull via openings termed foramina. ${ }^{[8]}$
Recent advances in CT have produced a growing need for precise information about optimal scanning positions for examining the morphological and metrical details of the foramina and canals in the base of the skull. Knowledge of the normal and variant positions of the canals and foramina of the skull base is important for radiologists, neurosurgeons and anatomists, because of the increasingly refined techniques available. ${ }^{[9]}$

\section{Material \& Method}

Thirty human skulls, available in the department of Anatomy, Dayanand Medical College and Hospital, Ludhian were studied after approval of hospital Ethics Committee. All the skulls selected were dry, complete \& showed normal anatomical features. Skulls showing parthological changes, evidence of any previous trauma or skeletal disorders were excluded from this study.

\section{Results}

Table no.1 Measurements of Foramen Magnum (in mm)

\begin{tabular}{|l|c|c|c|c|}
\hline Parameter & Mean & SD & Range & SEM \\
\hline MAPD & 35.38 & 3.22 & $30.3-43.44$ & 0.59 \\
\hline MTD & 27.81 & 2.58 & $20.62-31.56$ & 0.47 \\
\hline FMI & 17.16 & 1.56 & $14.69-21.07$ & 0.28 \\
\hline
\end{tabular}

Table No. 2 Distribution of range of MAPD of Foramen Magnum(in mm)

\begin{tabular}{|l|c|c|}
\hline Range of MAPD & No. of specimens & \%age of specimens \\
\hline $30.01-32.00$ & 4 & 13.33 \\
\hline $32.01-34.00$ & 6 & 20 \\
\hline $34.01-36.00$ & $\mathbf{7}$ & $\mathbf{2 3 . 3 3}$ \\
\hline $36.01-38.00$ & 6 & 20 \\
\hline $38.01-40.00$ & 5 & 16.67 \\
\hline $40.01-42.00$ & - & 6.67 \\
\hline $42.01-44.00$ & 2 & 100 \\
\hline Total & 30 & \\
\hline
\end{tabular}

Maximum number of cases in each part is highlighted. 
Table No. 3 Distribution of range of MTD of Foramen Magnum (in mm)

\begin{tabular}{|l|c|c|}
\hline Range of MTD & No. of specimens & \%age of specimens \\
\hline $20.01-22.00$ & 1 & 3.33 \\
\hline $22.01-24.00$ & 1 & 3.33 \\
\hline $24.01-26.00$ & 4 & 13.33 \\
\hline $26.01-28.00$ & 7 & 23.34 \\
\hline $28.01-30.00$ & $\mathbf{9}$ & $\mathbf{3 0}$ \\
\hline $30.01-32.00$ & 8 & 26.67 \\
\hline Total & 30 & 100 \\
\hline
\end{tabular}

Maximum number of cases in each part is highlighted.

Table No. 4 Distribution of range of Foramen Magnum Index

\begin{tabular}{|l|c|c|}
\hline Range of FMI & No. of specimens & \%age of specimen \\
\hline $14.01-15.00$ & 1 & 3.33 \\
\hline $15.01-16.00$ & 6 & 20 \\
\hline $16.01-17.00$ & $\mathbf{8}$ & $\mathbf{2 6 . 6 7}$ \\
\hline $17.01-18.00$ & 6 & 20 \\
\hline $18.01-19.00$ & 6 & 20 \\
\hline $19.01-20.00$ & 1 & 3.33 \\
\hline $20.01-21.00$ & 1 & 3.33 \\
\hline Total & 1 & 3.33 \\
\hline
\end{tabular}

Maximum number of cases in each part is highlighted

Table No. 5 Measurements of Intercondylar Distance (in mm)

\begin{tabular}{|l|c|c|c|c|}
\hline Parameter & Mean & SD & Range & SEM \\
\hline Anterior Intercondylar Distance & 17.25 & 1.91 & $11.78-19.80$ & 0.35 \\
\hline Middle Intercondylar Distance & 21.64 & 2.26 & $16.28-28.40$ & 0.41 \\
\hline Posterior Intercondylar Distance & 30.66 & 1.97 & $26.58-32.98$ & 0.35 \\
& & & & \\
\hline
\end{tabular}

Table No. 6 Distribution of range of Anterior Intercondylar Distance(in mm)

\begin{tabular}{|l|c|c|}
\hline $\begin{array}{l}\text { Range of Anterior } \\
\text { Intercondylar Distance }\end{array}$ & No. of specimens & \%age of specimens \\
\hline $10.01-12.00$ & 1 & 3.33 \\
\hline $12.01-14.00$ & - & - \\
\hline $14.01-16.00$ & 8 & 26.67 \\
\hline $16.01-18.00$ & 9 & 30 \\
\hline $18.01-20.00$ & $\mathbf{1 1}$ & $\mathbf{3 6 . 6 7}$ \\
\hline $20.01-22.00$ & 1 & 3.33 \\
\hline Total & 30 & 100 \\
\hline
\end{tabular}

Maximum number of cases in each part is highlighted. 
Table No. 7 Distribution of range of Middle Intercondylar Distance ( in mm)

\begin{tabular}{|l|c|c|}
\hline $\begin{array}{l}\text { Range of Middle } \\
\text { Intercondylar Distance }\end{array}$ & No. of specimens & \%age of specimens \\
\hline $16.01-18.00$ & 2 & 6.67 \\
\hline $18.01-20.00$ & 3 & 10 \\
\hline $20.01-22.00$ & $\mathbf{1 2}$ & $\mathbf{4 0}$ \\
\hline $22.01-24.00$ & 11 & 33.3 \\
\hline $24.01-26.00$ & 2 & 6.67 \\
\hline $26.01-28.00$ & - & - \\
\hline $28.01-30.00$ & 1 & 3.33 \\
\hline Total & 30 & 100 \\
\hline
\end{tabular}

Maximum number of cases in each part is highlighted

Table No. 8 Distribution of range of Posterior Intercondylar Distance (in mm)

\begin{tabular}{|l|c|c|}
\hline $\begin{array}{l}\text { Range of Posterior } \\
\text { Intercondylar Distance }\end{array}$ & No. of specimens & \%age of specimens \\
\hline $26.01-28.00$ & 2 & 6.67 \\
\hline $28.01-30.00$ & 10 & 33.3 \\
\hline $30.01-32.00$ & $\mathbf{1 1}$ & $\mathbf{3 6 . 6 7}$ \\
\hline $32.01-34.00$ & 6 & 20 \\
\hline $34.01-36.00$ & 1 & 3.33 \\
\hline Total & 30 & 100 \\
\hline
\end{tabular}

Maximum number of cases in each part is highlighted.

Graph 1 Distribution of range of MAPD of Foramen Magnum (in mm)

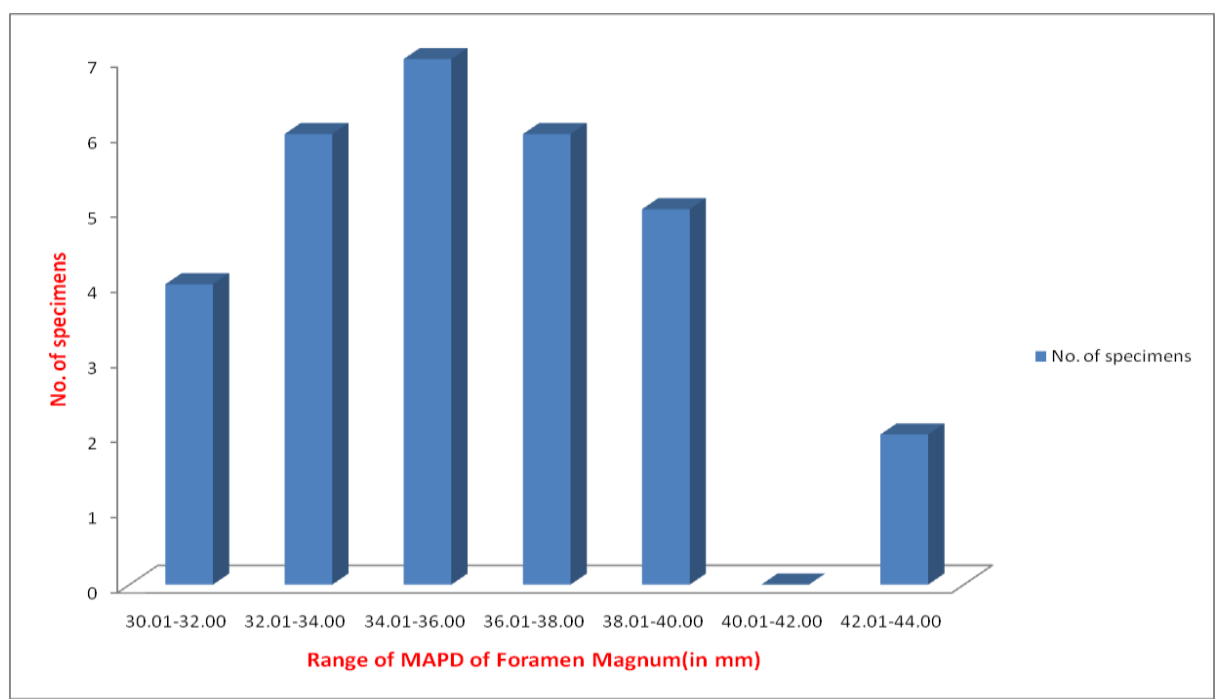


Graph 2 Distribution of range of MTD of Foramen Magnum (in mm)

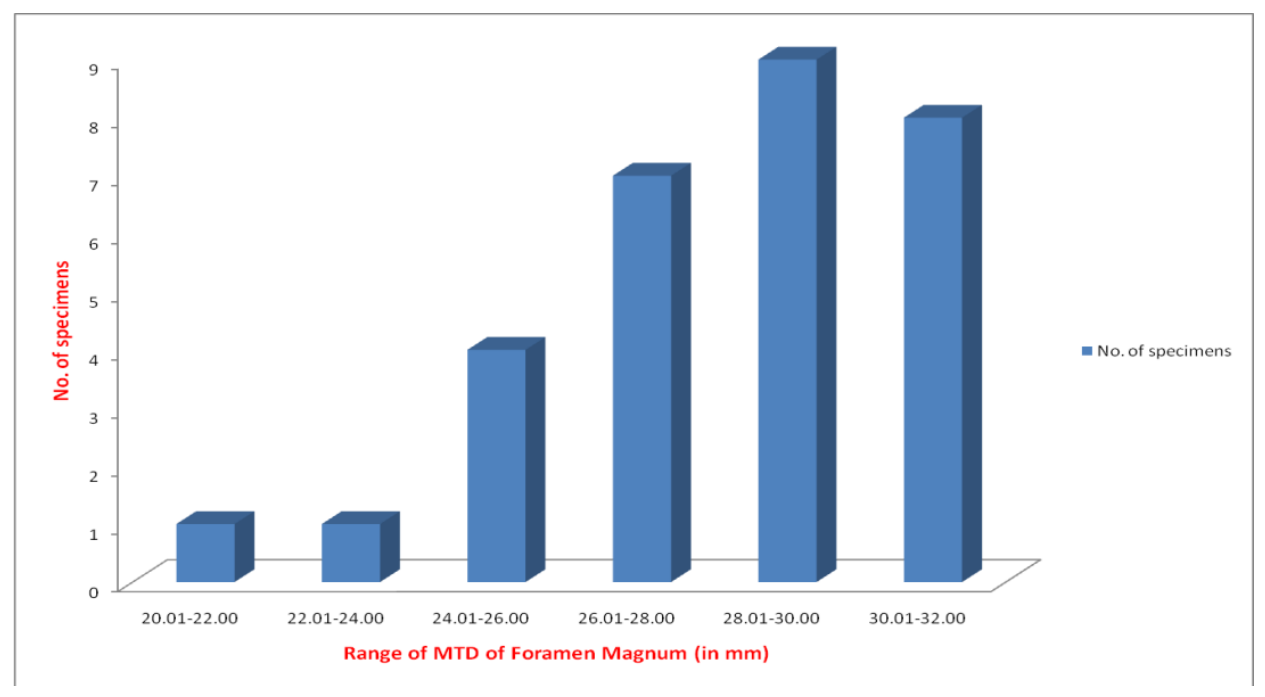

Graph 3 Distribution of range of Foramen Magnum Index

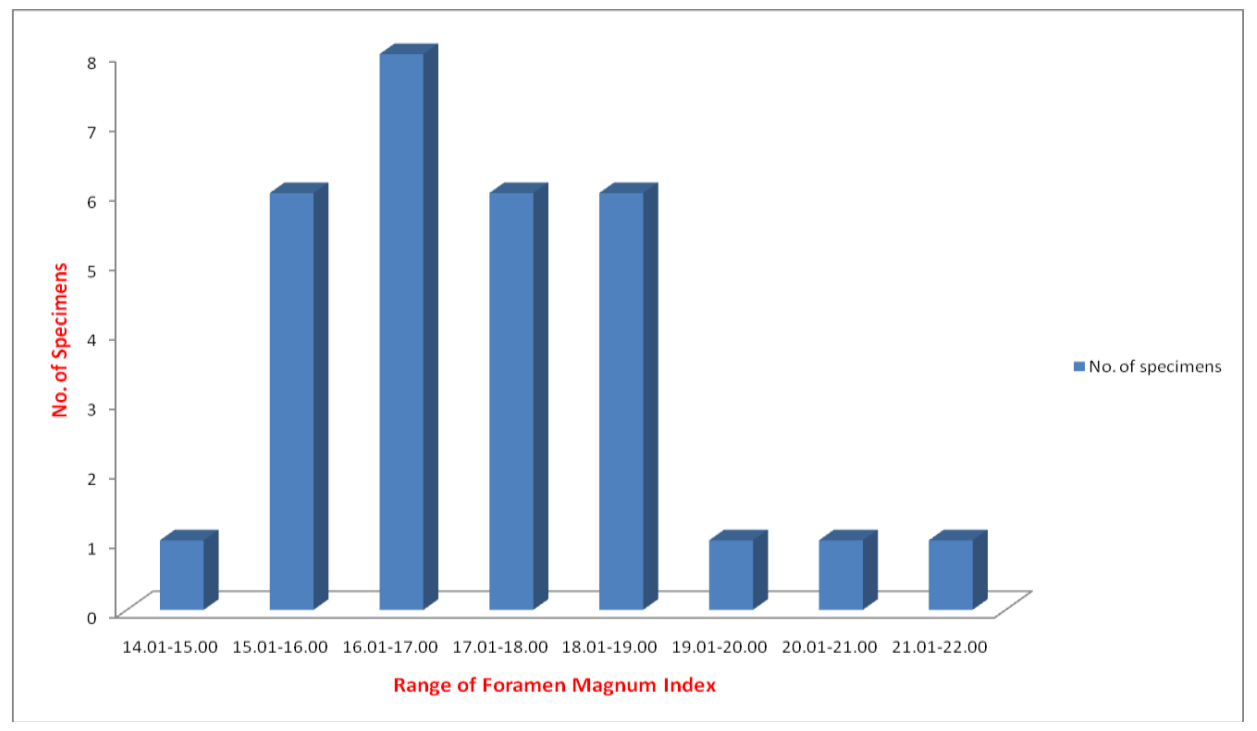

Graph 4 Distribution of range of Anterior Intercondylar Distance (in mm)

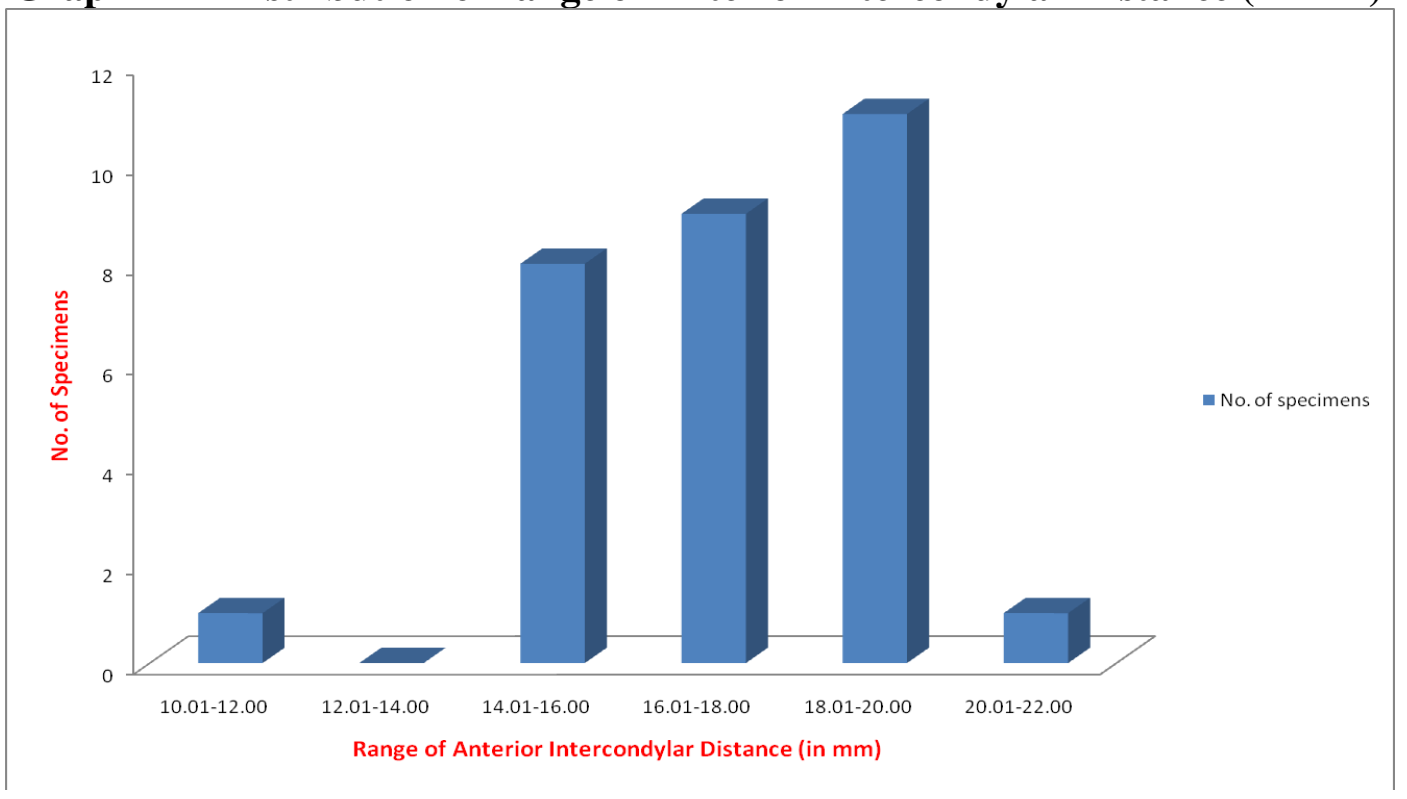


Graph 5 Distribution of range of Middle Intercondylar Distance ( in mm)

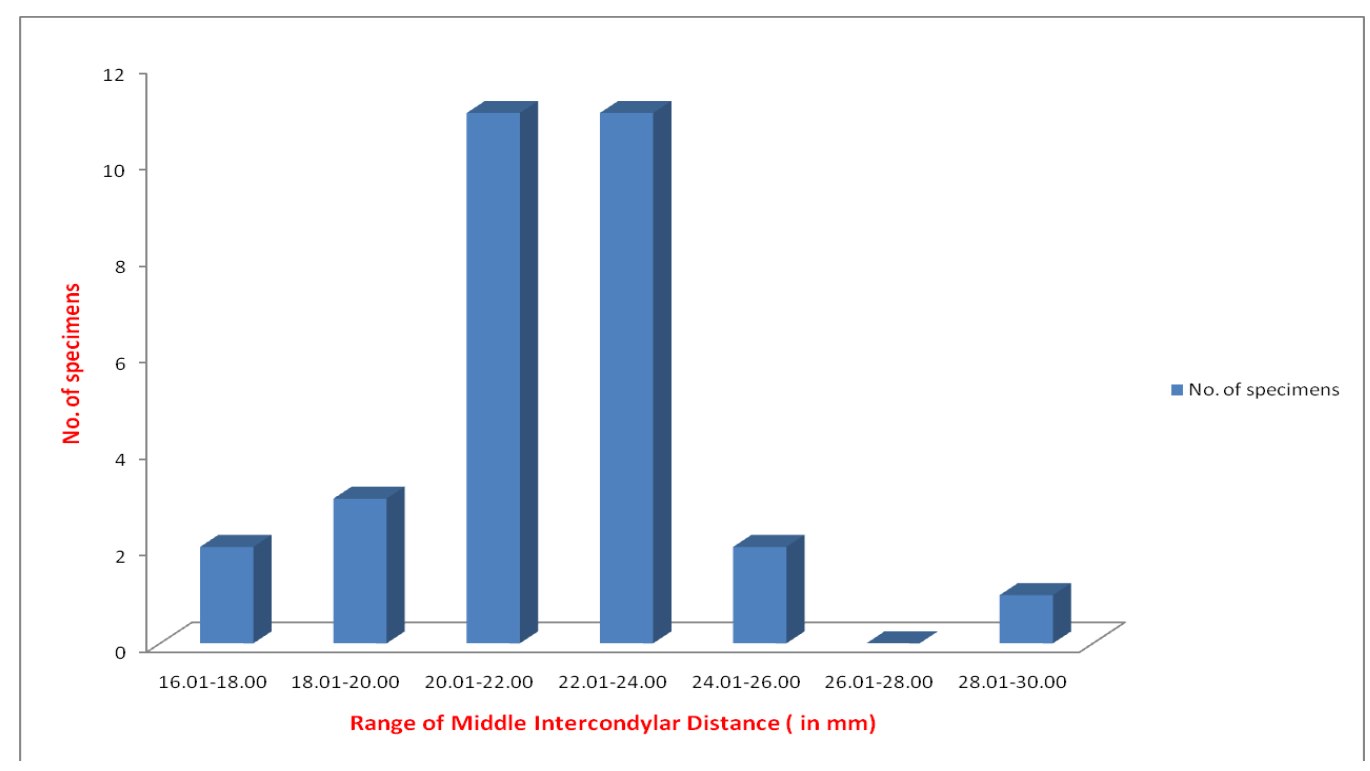

Graph 6 Distribution of range of Posterior Intercondylar Distance ( in mm)

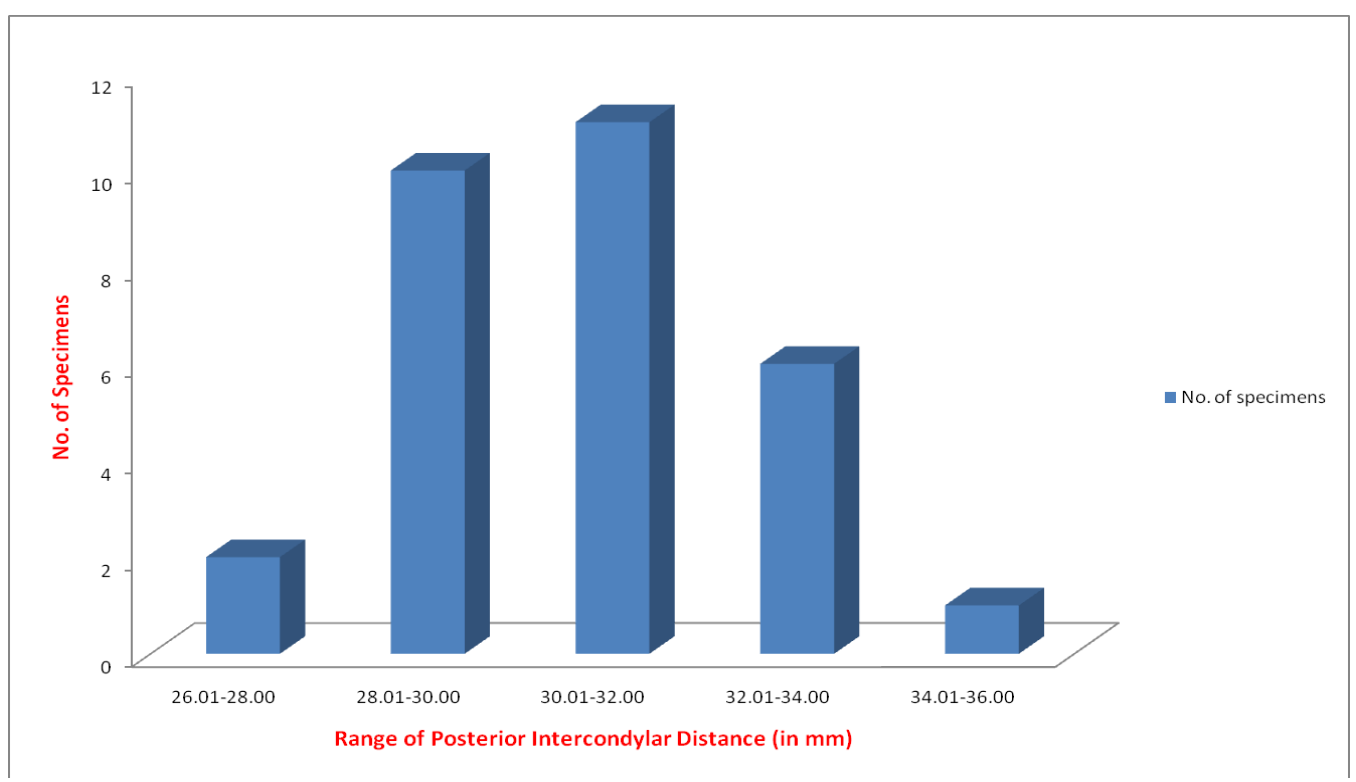



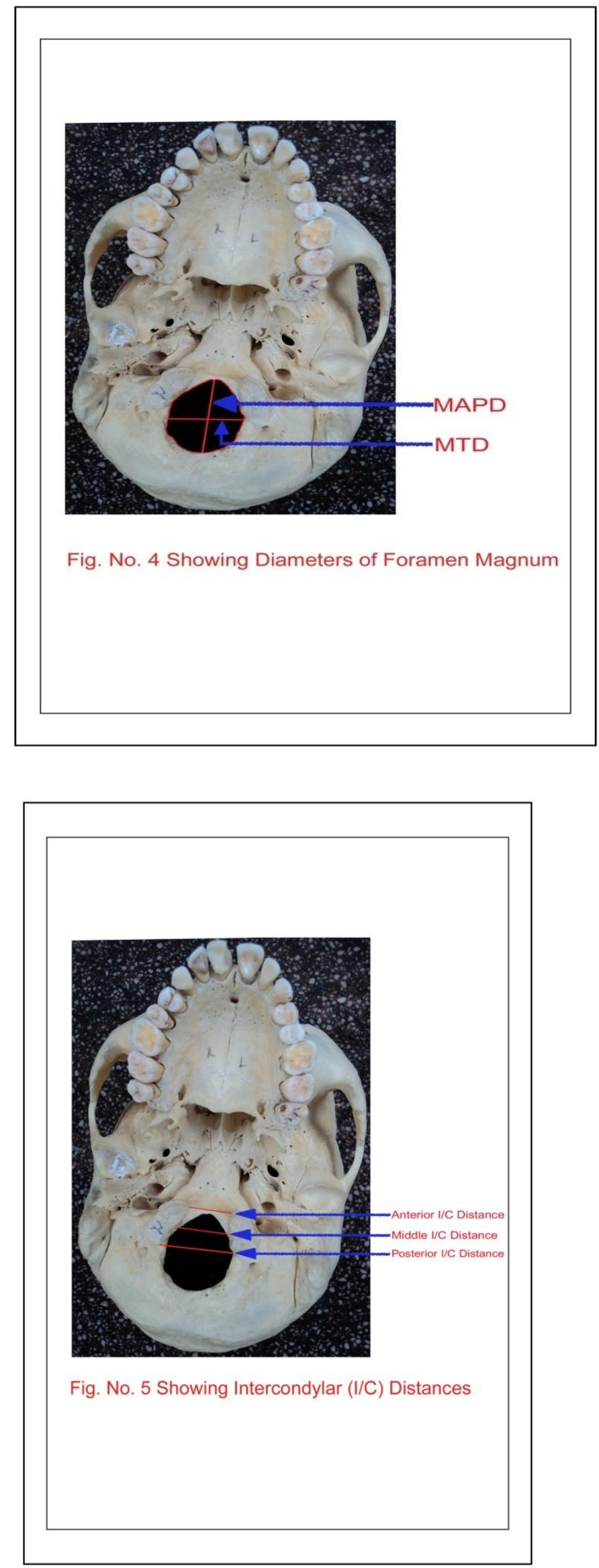

\section{SUMMARY AND CONCLUSION}

The present study was conducted on 30 adult dry human skulls ofunknown sex in the Department of Anatomy, Dayanand Medical College and Hospital, Ludhiana. The skull base foramina were studied regarding the normal morphometric values and particularly the deviations if any.

The present study had observed the variation in the measurements of skull base foramina which were differ from observations by the western studies.

Morphometric analysis of foramen magnum plays important role in transcondylar approach. As observed during the study, by and large all the measurements of foramen magnum, which were taken, were found to be a few millimeters higher than the western population

\section{REFERENCES}

1. Nemzek WR, Brodie HA, Hecht ST, Chong BW, Babcook CJ, Seibert JA. MR, $\mathrm{CT}$, and Plain film imaging of the developing skull base in fetal specimens. AJNR. 2000; 21:1699-706

2. Standring S. External skull. In: Standring S, Borley NR, Collins P, Crossman AR, Gatzoulis MA, Healy JC, et al. Gray's Anatomy: The Anatomical Basis of Clinical Practice. 40th ed. Elsevier Churchill Livingstone; 2008: p. 409-21

3. Karasu A, Cansever T, Batay F, Sabanci PA, Al-MeftiO.The microsurgical anatomy of the hypoglossal canal. SurgRadiol Anat. 2009; 31:363-7

4. Muthukumar N, Swaminathan R, Venkatesh G, Bhanumathy SP. A morphometric analysis of the foramen magnum region as it relates to the transcondylar approach. ActaNeurochir (wien) 2005; 147(8): 889-95

5. Naderi S, Korman E, Citak G, Guvencer M, Arman C, Senoglu M. et al. Morphometric analysis of human occipital condyle .Clinical neurology and neurosurgery 2005: 107; 191-9 
6. IdowuOE.The jugular foramen $-\mathrm{a}$ morphometric study. Folia Morphol. 2004; 63(4): 419-22

7. GusmaoS,Oliveira M, Tazinaffo U, Honey CR. Percutaneous trigeminal nerve radiofrequency rhizotomy guided by computerized tomography fluoroscopy. J.Neurosurg 2003; 99:785-6

8. Elias MG, Silva RB, Pimentel ML, Cardoso VTS, Rivello T, Babinski MA. Morphometric analysis of the infraorbital foramen and accessories foraminas in Brazilian Skulls.Int J Morphol.2004; 22(4): 273-8

9. Aziz SR, Marchena JM, Puran A. Anatomic characteristics of the infraorbital foramen: A cadaver study. J Oral Maxillofac Surg. 2000; 58(9): 992-6 